\title{
Systemic Design for a circular textile: towards a systemic change
}

\author{
Eliana Ferrullia, Silvia Barbero \\ aPolitecnico di Torino \\ *Corresponding author e-mail: eliana.ferrulli@polito.it
}

\begin{abstract}
:
The Circular Economy Action Plan provides a roadmap of actions aiming at accelerating the transformational change required by the European Green New Deal. The textile sector has been identified amongst the industrial sectors recognized of great potential for the reconversion from linear to circular economy. Being one of the world's most globalized, polluting, and exploitative industries throughout its whole value chain, there is an urgent need for the textile sector to make a transformative and radical shift towards a Circular Economy.

Since 2015, different Circular Economy actions have been implemented across different industrial sectors and at the micro / meso / macro level, but a systemic and cross-sectoral effort is needed to cope with such a complex challenge. Thus, this paper contributes to the ongoing discussion around the topic of design for sustainability aiming to understand how a systemic design approach can foster the transition towards a circular textile value chain.
\end{abstract}

\section{Keywords: Circular Economy; Systemic Design; Sustainability; Textile}

\section{Introduction}

We are currently living in an era of huge transformations which require both top-down and bottom-up strategies to cope with uncertainty and change (Krauz, 2016). Among the complex challenges that we are facing nowadays, the most recent Covid-19 pandemic has shown the fragility of our global economy and the importance of more reliable and resilient local systems. Indeed, nowadays, almost every government worldwide is facing the urgency to shift towards sustainability, and Circular Economy (CE) has been identified as the main road to convert our linear and resource-intensive economy into a restorative one (MacArthur, 2013).

The Circular Economy Action Plan, signed again in 2020 by the European Union (EU), provides a roadmap of actions on a quadruple helix perspective (university - companies - civil society government), aiming at accelerating the transformational change required by the European Green New Deal. With the aim of "closing the loop" of products' life cycles through resource-efficient processes, recycling, and reuse, the EU has identified specific industrial sectors which have been recognized of great potential for reconversion from a linear "take-make-dispose" productive model to a circular one. 
The textile sector is one of these, together with electronics and ICT, batteries and vehicles, packaging, plastics, construction and buildings, food, water, and nutrients. With more than 750 thousand companies, around 4 million people employed across EU, and EUR 630 billion (Eurostat, 2017), the textile sector thus makes an important contribution to the European economy. At the same time, it is one of the world's most polluting industries, registering negative environmental impacts throughout the whole value chain, from raw materials processing - farming, breeding, or extracting - to final dismantling. Moreover, the textile sector is regularly implicated in cases of exploitive working conditions and modern slavery (Vercalsteren et al., 2019). Although big brands are taking action by selecting new and "greener" materials, a sustainable transition shouldn't be taken for granted unless it is framed in a systemic change.

Evidence from literature on $\mathrm{CE}$ in the textile sector shows that it is a subject attracting attention across a variety of disciplines and journals, with a growing trend in the number of publications since 2013 (Jia et al., 2020). In this framework, academic contributions from the design field remain scattered and mainly focused on products and fashion, with limited knowledge on deep sustainability issues that go beyond the simple material selection (Karell \& Niinimäki, 2020). Given the complexity of the textile value chain, a more holistic understanding and practices are required, to make a transformative and radical shift towards a CE. Thus, this paper suggests the potential for Systemic Design to support the transition towards a circular textile value chain. On that view, two central questions guide the research:

1.How are design approaches currently supporting the textile industry in the transition towards a Circular Economy?

2. What are the processes and tools that Systemic Design can suggest to broaden the understanding of sustainability in the textile sector and enhance a regenerative culture by design?

This paper is organized as follows: in the first section a brief literature review on CE, textile sector and design for sustainability set the background for this paper; the subsequent section deepens the systemic design approach, methodology, and contribution to design knowledge in the sustainability domain; it follows the discussion paragraph which investigates Systemic Design usefulness for the transition towards a circular textile sector. The paper concludes with final remarks on the contributions of this research and future works.

\section{Background research}

This work is an initial exploratory study on the Systemic Design role in the circular textile value chain.

In the following paragraphs two strands of literature, one on $\mathrm{CE}$ and one on design for sustainability in the textile sector, provide the theoretical background for this paper. Through the analysis of these strands, it has been possible to outline the state of the art of design knowledge and practices in the textile sector, inside a CE framework, setting the ground for the exploratory study.

\subsection{Circular Economy concept and state of the art in Europe}

The concept of $\mathrm{CE}$ is receiving increasing attention worldwide as a way to shift from a linear "takemake-dispose" productive model, towards a regenerative and restorative one (MacArthur, 2013).

With the aim of "closing-the-loop" in production patterns, CE promotes alternative productive and economic models by increasing resource efficiency and keeping materials circulating in the economy 
for a longer time, to achieve a better balance and harmony between economy, environment, and society (Ghisellini et al., 2016). The appeal of CE is that it promises to reconcile environmental and economic goals, thus the concept has gained traction and resonance in policy, business, and academia (Baldassarre et al., 2019; Hobson et al., 2018), with an exponential trend of reports and publications starting from 2014 (Geissdoerfer et al., 2017).

Although the concept is gaining momentum especially in the last decade, it emerged initially in the 1970s (Fitch-Roy et al., 2019) laying its foundation in the theoretical concepts of cradle-to-cradle (McDonough W. and Braungart M., 2002), laws of ecology (Commoner, 1971), looped and performance economy (Stahel, 2010), regenerative design (Lyle, 1994), industrial ecology (Frosch \& Gallopoulos, 1989; Graedel and Allenby, 1995), biomimicry (Benyus, 2002), and the blue economy (Pauli, 2010), as summarized in a previous review by Geissdoerfer et al. (2017).

$\mathrm{CE}$ concepts and practices are also influencing policymakers, governments, and intergovernmental agencies at the local, regional, national, and international level (Geissdoerfer et al., 2017) and the EU has been a pioneer in that sense, with different policies and frameworks that promote $\mathrm{CE}$ in various industries, businesses, and services, and across micro-level (i.e., initiatives by single firms), mesolevel (i.e., initiatives by eco-industrial parks) and macro-level (i.e., initiatives at city, province, regional, national level)(Mhatre et al., 2021).

Evidence from literature shows that macro-level initiatives predominate CE's implementation in the EU (Mhatre et al., 2021; Nikolaou et al., 2021), while meso-level initiatives are the least implemented (Mhatre et al., 2021). Moving to the sectors, it seems that waste management, electrical and electronic equipment industries and construction industries are pioneers in CE implementation, and recycling is the most widely used circular strategy for looping back materials into the system (Mhatre et al., 2021; Kern et al., 2020).

\subsection{The textile sector and the evolution of design for sustainability}

Within the Circular Economy Action Plan, firstly launched in 2015 (European Commission, 2015) and then reconfirmed in 2020 (European Commission, 2020) the European Commission identified textiles (apparel and fabrics) as a priority product category for the CE. The Action Plan establishes a series of initiatives along the entire life cycle of products, aiming to ensure more waste prevention and resource longevity, through specific legislative and non-legislative measures. These measures and initiatives address how products are designed, promote circular economy processes, encourage sustainable consumption, by targeting specific production areas in which CE brings more added value. The textile sector is one of these, being a highly complex and globalized market, affecting every country worldwide both directly or indirectly, and strongly connected to high environmental, climate, and social impacts (Vercalsteren et al., 2019).

Amongst the environmental impacts to which the textile sector is associated, there's the depletion of material resources and water, land use, greenhouse gas emissions, and chemicals' toxicity (JRC, 2014). While the social impacts are mainly connected to labor exploitation, precarious physical and infrastructural working conditions, gender inequality, and lower overall operating costs (Vercalsteren et al., 2019; Ecopreneur.eu, 2019). Additionally, while Europe is ranked as the second-largest textile exporting region in the world, textile and clothes are currently mainly produced in China, Bangladesh, Turkey, India, Cambodia, making the EU a net importer of textiles (Vercalsteren et al., 2019; Ecopreneur.eu, 2019). 


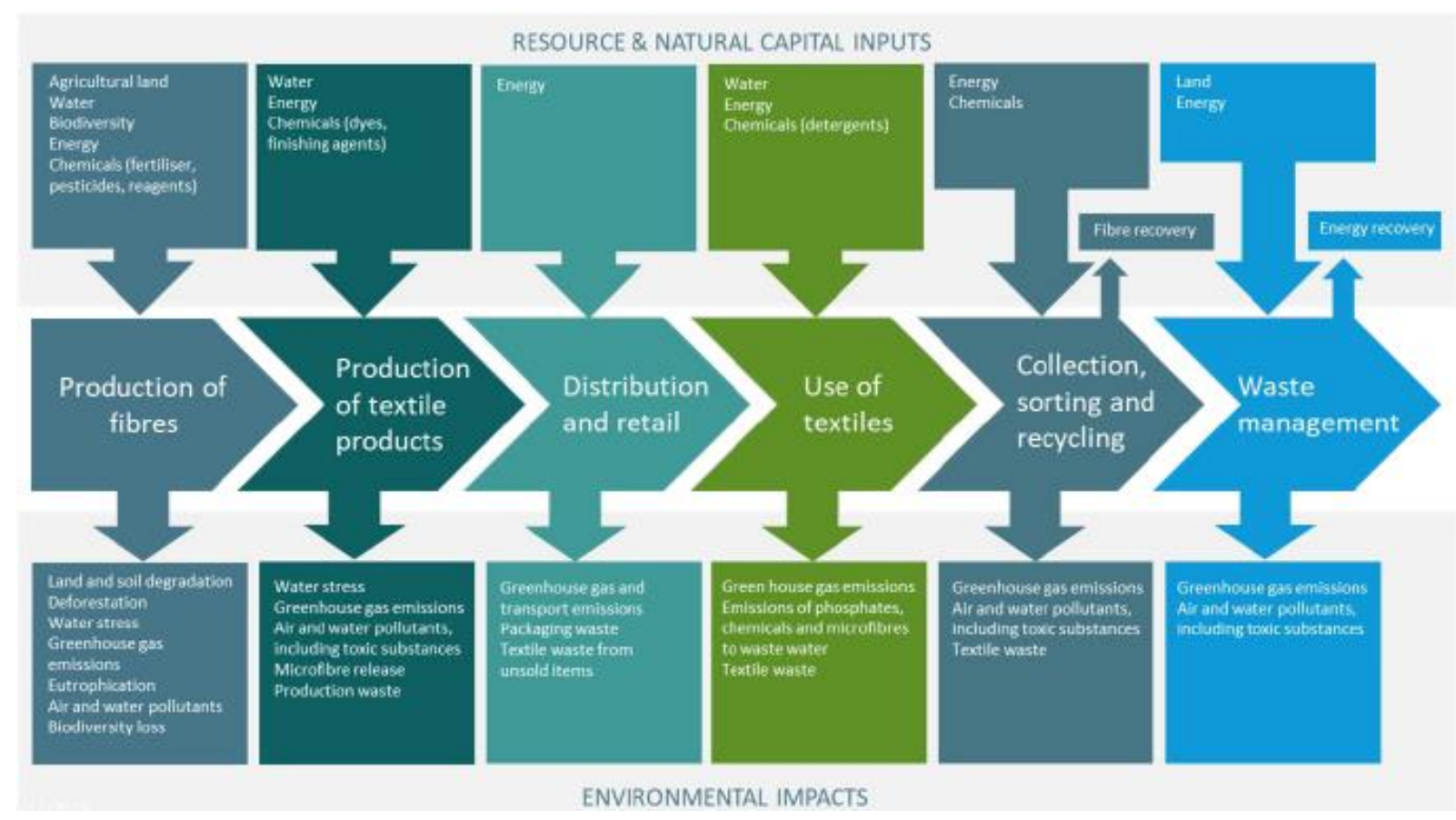

Figure 1. Environmental impacts across the textile life-cycle. Retrieved from: EEA and ETC/WMGE, based on EEA (2014)

Given the strong linearity and globalization of the whole value chain, this makes it particularly challenging to ensure transparency and traceability in the sector. There is thus an urgent need for the textile sector to make a systemic transformative shift towards CE.

In such a scenario, Design expertise is increasingly understood as relevant and useful in sustainability and CE transition. Initially John Thackara (2005), and more recently Ellen MacArthur Foundation (2013), have defined the CE as restorative and regenerative by design since around $80 \%$ of environmental impacts are determined at the design stage. Evolving from the initial concept of "design for sustainability" (or "sustainable design") (Bhamra \& Cooper, 2007), there's increasing attention of the design field towards more sustainable models of production and consumption aiming to "closing the loop" (Mestre \& Cooper, 2017).

Through the literature review performed for the scope of this paper, the design knowledge in the transition towards a circular textile sector seems to be under-explored and fragmented. From a broader perspective, the majority of the articles mainly investigates fashion and garments, while home textiles have received very little attention in academic research (Lehner et al., 2020). Several examples focus on "recycling" as a strategy (Karell \& Niinimäki, 2019; Lehner et al., 2020; Sandvik \& Stubbs, 2019) following the European trend, while the other strategies - i.e., reuse, reduce, upcycle - are less investigated. Moreover, the subject of circular textile seems to be mainly investigated by textile and fashion designers, focused more on products (Moorhouse \& Moorhouse, 2017), but very few on the broader process.

This last point is critical for the transition towards a circular textile value chain as the challenges of a complex sector need to be addressed by complex solutions. Indeed, according to Karell \& Niinimäki (2020) materials selection steers the sustainability-related discussion and guides design practices the most. The authors also witnessed a limited knowledge of designers in sustainable design strategies, processes, or tools and a lack of collaboration inside the company's departments, thus limiting designers' overall impact in tackling the current fashion system. The study has been later confirmed and widened by Cristina Dan \& Østergaard (2021) who highlighted organizational, structural, operational, and attitudinal barriers in the context of the designer's role within organizations shifting 
towards CE, calling for a wider sustainability-related knowledge and systemic organizational changes. Finally, although academic research has expanded the knowledge on sustainable design and suggested different tools over the years, still this theoretical knowledge has not been fully translated into workable industry practices. Consequently, an overall consensus evidenced in literature is related to the need for both more stakeholders' collaboration (Karell \& Niinimäki, 2020; Ghisellini et al., 2016; Lane et al., 2015; Mestre \& Cooper, 2017) and for a systemic approach (Cristina Dan \& Østergaard, 2021; Lane et al., 2015; Goldsworthy \& Early, 2018).

Grounded on these premixes the following paragraph deepens the systemic design approach, and how it broadens design's sustainability-related knowledge, thus suggesting its potential for a circular textile value chain.

\section{Systemic Design methodology \& approach}

From the integration of Systems Thinking with the design discipline, has emerged Systemic Design, which focuses on a holistic approach applied to products, services, and systems (Jones P., 2018).

With its theoretical foundations rooted in Cybernetics (Wiener, N., 1948), General Systems Theory (Von Bertanlaffy, 1950, 1968), Systems Thinking (Capra, 1995), Industrial Ecology (Preston, 2012), and Design Thinking (Buchanan, 1992), Systemic Design has broadened the field of design, by combining tangible skills with a more holistic view given from system thinking. As Jones (2014) elucidated:

Systemic Design brings human-centered design to complex, multi-stakeholder service systems. It adapts from known design competencies - form and process reasoning, social and generative research methods, and sketching and visualization practices - to describe, map, propose and reconfigure complex services and systems. (Jones P., 2014)

The emergence of Systemic Design reflects the increasing complexity and "wickedness" of todays' challenges (i.e., climate change, sustainable development), trespassing traditional design's skills and methods to go beyond a tangible outcome, towards intangible goals like sustainable behaviors and development. The concept of wicked problem - meaning "a trivial, enduring and interconnected situation that cannot be solved immediately due to its inner complexity and its exogenous/endogenous relations" (Rittel and Webber,1973) - has been described also by Buchanan (1992). Focusing on the role of design in approaching wicked problems, the author has emphasized design's ultimate goal to shift towards a resilient, fair, and sustainable society.

From that perspective emerged the Systemic Design approach that designs the material and energy flows from one component of the system to another, and transforms outputs of one process into inputs for another one. The ultimate goal of Systemic Design is to tend to zero emissions and generate local resilient socio-technical systems (Bistagnino, 2011).

Systemic Design methodology has been described by Battistoni et al. (2019) in the following steps:

- Holistic Diagnosis (HD): it consists of a desk and field research combined to investigate the context of action on the economic, social, and environmental aspect, considering the flows of energy and matter;

- Definition of challenges and opportunities: Starting from the framework outlined in the HD, connections and influences are analyzed in order to outline the challenges and opportunities of future scenarios. Problems are regarded as leverages for change from which the project can be defined and started; 
- Design the system: A new production model is designed whose aim is to tend to zero emissions by optimizing energy and material flows and by enhancing waste as a resource;

- Outcomes Evaluation: Consists in the assessment of the environmental, economic, and social benefits belonging from the new production model;

- Implementation: of the proposed designed system in the given context and consequent estimation of the new economic activities feasibility;

- Results analysis and feedback: Consists in the assessment of the implemented system, ensuring it to be autopoietic.

One of the outputs of this methodology is the creation of giga-maps, where a significant amount of information is "digested" into easy-reading diagrams, schemas, and scenarios, making the information accessible and graspable (Sevaldson, 2011). The giga-maps practically allows the visualization and examination of the challenges, supporting stakeholders' collaborations and a transdisciplinary dialogue on a quadruple helix perspective, meaning among universities, companies, civil society, and government.

Through the mapping and visualization of resources' flows, this approach favors the unlocking of hidden local potentialities and supports the active collaboration among stakeholders, enhancing or generating new locally-based value chains (Barbero, 2012). On that view, Systemic Design investigates the context in a deeper and broader perspective, surpassing the small scale, towards a more holistic view of the context, which takes into consideration its socio-economic-cultural layers. Building from that, Systemic Design creates synergic linkages between the productive and natural realm of a given territory, by straightening the socio-economic systems connected to that territory, within a long-term vision (Giraldo Nohra et al., 2020).

Based on these premises, in this article we argue how a systemic design approach can foster the transition towards a circular textile value chain, contributing to shortening and interconnecting the different value chains, through the enhancement of local assets, and favoring stakeholders' collaboration.

\section{Discussion \& conclusions}

The analysis performed until now shows that there's an urgent need for our productive and economic systems to shift towards more sustainable development.

Movements worldwide are thus claiming the need to slow down and rethink the basis of our productive and economic realms to re-balance the overload of production, which inevitably causes problems with waste management and environmental pollution. Whether they are more radical or moderate, concepts like "degrowth" (Schneider et al., 2010; Martinez-Alier, 2012; Demaria et al., 2013), "steady-state" (Pirages, 1977), and "decolonization", as well as the "slow movements"spanning from living, to food and fashion - are the counter-effect of a Western world who is reacting to the fast-paced rhythms and the unwanted implications of the current polluting and exploitative markets and industries. The general claim, which is also partially absorbed in the concept of CE, is the urgent need to reconceive the way we produce, consume and behave within the "doughnut of social and planetary boundaries" (Raworth K., 2017).

The textile sector, amongst the others, is representative of this condition given the complex challenges to which it is associated. Indeed, it has been identified as one of the critical sectors to which Europe is addressing its funds, through the Circular Economy Action Plan. 
In this framework, design has been recognized as a relevant player for this transition. Indeed, public and private institutions worldwide, including the European Commission, refer to the claim that $80 \%$ of the environmental and social impacts of a product are determined at the design stage. Despite the persistence of this quote over the last two decades, literature shows that designers' sustainable impact into companies' practices is still limited (Karell \& Niinimäki, 2020). On that view, the first central question that guided this research was:

1.How are design approaches currently supporting the textile industry in the transition towards a Circular Economy?

First of all, much attention is paid to fashion and garments, while home textiles are under-explored (Lehner et al., 2020), thus partially addressing the textile sector which includes both fashion and apparel. Secondly, there is a gap in translating academic research on sustainable design into workable industry practices. Indeed, while the sustainability-related discussion is constantly growing with new knowledge and tools in academia, "sustainable" materials selection is what guides design practices the most into the real-world industry (Karell \& Niinimäki, 2020). This reveals a limited knowledge of designers in framing the sustainability discourse on a broader perspective that includes the social, environmental, and economic domain, so the sustainable design's deeper significance has still to be recognized (Stebbing and Tischner 2015). Also, the designer's role inside the company is limited according to Cristina Dan \& Østergaard (2021) who reported organizational, structural, operational, and attitudinal barriers. This calls for three important actions needed to broaden designers' knowledge and impact and address a deeper change into the current fashion system: first of all, the need for a strong focus on sustainability in design education curricula (Vercalsteren et al., 2019); secondly, to increase designers' collaboration inside companies' departments and outside with external stakeholders (Karell \& Niinimäki, 2020; Mestre \& Cooper, 2017; Ghisellini et al., 2016; Lane et al., 2015); third, a systemic approach.

Systemic Design combines systems thinking and design practices, framing its practices into a more holistic understanding of sustainable-related knowledge. Thus, this paper suggests its potential to support the transition towards a circular textile value chain. In that regard, a second question has been asked:

2. What are the processes and tools that Systemic Design can suggest to broaden the understanding of sustainability in the textile sector and enhance a regenerative culture by design?

As explained in a previous section, Systemic Design is able to holistically conceive products, services, and systems, together with their interconnections, by combining systems thinking and design practices. It contributes to shortening and interconnecting the different value chains, through the enhancement of local assets, and favoring stakeholders' collaboration. Table 1 presented below briefly outlines how Systemic Design methods and tools can address the current challenges in the textile sector, contributing to the ongoing discussion on circular textile transition.

Table 1. Textile challenges addressed by Systemic Design.

\begin{tabular}{ll}
\hline $\begin{array}{l}\text { Textile } \\
\text { Challenges }\end{array}$ & Textile challenges addressed by Systemic Design \\
\hline $\begin{array}{l}\text { Globalized value } \\
\text { chain }\end{array}$ & $\begin{array}{l}\text { Through the Holistic Diagnosis, Systemic Design identifies the hidden assets of } \\
\text { a territory connected to its socio-economic-material culture, straightening a } \\
\text { regional and regenerative manufacturing }\end{array}$ \\
\hline $\begin{array}{l}\text { Low transparency } \\
\text { \& traceability }\end{array}$ & $\begin{array}{l}\text { With the mapping and visualization of material and resources' fluxes, the } \\
\text { value chain is geographically defined and clearly displayed to consumers }\end{array}$ \\
\hline $\begin{array}{l}\text { Environmental } \\
\text { impact }\end{array}$ & $\begin{array}{l}\text { Systemic Design methodology performs a broader analysis not just on the } \\
\text { material selection but, more holistically, on the entire value chain. Through }\end{array}$ \\
\hline
\end{tabular}




\begin{tabular}{ll}
\hline & $\begin{array}{l}\text { the connection of different value chains, closed and open loops feed each } \\
\text { other at multiple scales, reducing the environmental, impact as a waste of } \\
\text { one production process is seen as a resource of another one }\end{array}$ \\
\hline Social impact & $\begin{array}{l}\text { The production isn't set on a market-driven perspective, rather on value- } \\
\text { driven assets emerging from the HD. Societal assets are taken into } \\
\text { consideration as a strong foundation to build a resilient economic and } \\
\text { productive system connected to the given territory. }\end{array}$ \\
\hline
\end{tabular}

Therefore, Systemic Design enables stakeholders' collaboration through design tools based on participatory methods and visualization practices, acting as a mediator among technicians, economists, humanists, and others (Celaschi et al., 2013) and on a quadruple helix perspective. Through the connection of different value chains, Systemic Design can contribute to enhancing collaboration among industries, creating links and exchange patterns, in both closed and open loops that feed each other. From that perspective, Systemic Design may address the gap found in the literature regarding the lack of meso level initiatives (Mhatre et al., 2021) supporting future policies in the creation of industrial eco-park or industrial symbiosis initiatives.

Furthermore, with its capacity to holistically frame the problems and their interconnection, Systemic Design aims to support fashion and textile designers, as well as other stakeholders involved in the textile sector, not only in materials' choice and recycling but, more broadly, on strategic and systemic choices across the whole value chain.

Finally, following the discourse of Sumter D. et al. (2021) who recently performed a study investigating the key competencies for design in a CE, it emerged that "Circular Systems Thinking" and "Circular Materials and Manufacturing" are two new competencies identified for the next generation of design, besides the seven already validated in a previous study. This internationally validated set of interlinked competencies provides a foundation for the growing interest in circular design, and Systemic Design absorbs these logics into its methods and processes.

Although there's an overall consensus both inside and outside academia, on the need for a systemic approach for the textile industry, there are still few projects that translate this need into practice. Among these, Mistra Future Fashion or Trash-2-Cash are transdisciplinary projects that received considerable financial support to apply a systemic approach among multidisciplinary teams aiming to design sustainable and novel practices for the fashion system. Although not exhaustively, their success proves there is ample room for Systemic Design to grow in the circular textile sector. Given the complex and wicked problems that this transition requires, this momentum must not be missed and expertise such as Systemic Design needs to be at the forefront in striving for a systemic change.

\section{Limitations \& future works}

This study aimed to contribute to the ongoing discussion around the topic of design for sustainability and presented the Systemic Design potential to support the transition towards a circular textile value chain. Despite its limitations being an initial exploratory study, the main contribution of this paper is theoretical and it stands in deepening the Systemic Design methodology, approach, and usefulness in the transition towards a CE.

Future works might consist in testing the Systemic Design approach in individual or multiple case studies, conducted in specific industrial contexts such as industrial clusters. In this context, it might be beneficial to understand and test how the Systemic Design approach combines a single company's sustainable strategies into a more holistic perspective and how it broadens or re-designs the logic of 
the whole industrial cluster, through the combination of different value chains that may be not strictly related to the textile sector. Thus, future experimentation might consist in testing the systemic design approach presented, by collecting empirical data both at the micro and meso level.

\section{References}

Baldassarre, B., Schepers, M., Bocken, N., Cuppen, E., Korevaar, G., \& Calabretta, G. (2019). Industrial Symbiosis: towards a design process for eco-industrial clusters by integrating Circular Economy and Industrial Ecology perspectives. Journal of Cleaner Production, 216, 446-460. https://doi.org/10.1016/j.jclepro.2019.01.091

Barbero, S. (2012). SyStemic energy networkS, Vol. 1. The theory of Systemic Design applied to energy sector (Vol. 1). Lulu. com.

Battistoni, C., Giraldo Nohra, C., \& Barbero, S. (2019). A systemic design method to approach future complex scenarios and research towards sustainability: A holistic diagnosis tool. Sustainability, 11(16), 4458.

Benyus, J. M. (2020). Biomimicry: innovation inspired by nature.

Bhamra, T., Lofthouse, V., and Cooper, R. (ed.) (2007). Design for sustainability : a practical approach. Design for Social Responsibility series, Farnham, Gower.

Bistagnino, L. (2011). Systemic design: designing the productive and environmental sustainability. Slow Food Editore, Cuneo, Bra.

Brezet, H. (1997). Ecodesign-A promising approach to sustainable production and consumption. United Nations Environmental Programme (UNEP).

Buchanan, R. (1992). Wicked problems in design thinking. Design issues, 8(2), 5-21.

Capra, F. (1996). The web of life: A new scientific understanding of living systems. Anchor.

Ceschin, F., \& Gaziulusoy, I. (2016). Evolution of design for sustainability: From product design to design for system innovations and transitions. Design Studies, 47, 118-163.

Commoner, B. (1971). The closing circle. Nature, man, and technology (pp. 6-26).

Cristina Dan, M., \& Østergaard, T. (2021). Circular Fashion: The New Roles of Designers in Organizations Transitioning to a Circular Economy. The Design Journal. https://doi.org/10.1080/14606925.2021.1936748

De Pauw, I. C. (2015). Nature-inspired design: Strategies for sustainable product development.

Demaria, F., Schneider, F., Sekulova, F., \& Martinez-Alier, J. (2013). What is degrowth? From an activist slogan to a social movement. Environmental Values, 22(2), 191-215.

Den Hollander, M. C., Bakker, C. A., \& Hultink, E. J. (2017). Product design in a circular economy: Development of a typology of key concepts and terms. Journal of Industrial Ecology, 21(3), 517525.

Ecopreneur.eu (2019) Circular fashion and textile producing countries. A first inventory of the potential impacts of an EU circular fashion industry on non-European textile producing countries. Retrieved May 14, 2021, from www.ecopreneur.eu

Fitch-Roy, O., Benson, D., \& Monciardini, D. (2019). Going around in circles? Conceptual recycling, patching and policy layering in the EU circular economy package. Environmental Politics. https://doi.org/10.1080/09644016.2019.1673996

Frosch, R. A., \& Gallopoulos, N. E. (1989). Strategies for manufacturing. Scientific American, 261(3), 144-153.

Geissdoerfer, M. and Savaget, P. and Bocken, N.M.P. and Hultink, E.J. (2017) 'The circular economy a new sustainability paradigm?', Journal of cleaner production., 143 . pp. 757-768. 
Ghisellini, P., Cialani, C., \& Ulgiati, S. (2016). A review on circular economy: The expected transition to a balanced interplay of environmental and economic systems. Journal of Cleaner Production, 114, 11-32. https://doi.org/10.1016/j.jclepro.2015.09.007

Giraldo Nohra, C., Pereno, A., \& Barbero, S. (2020). Systemic design for policy-making: Towards the next circular regions. Sustainability, 12(11), 4494.

Goldsworthy, K., \& Earley, R. (2018). Circular Transitions: Textile design and the circular economy.

Goldsworthy, K., Earley, R., \& Politowicz, K. (2018). Circular Speeds: A Review of Fast \& Slow Sustainable Design Approaches for Fashion \& Textile Applications. Journal of Textile Design Research and Practice, 6(1), 2-4. https://doi.org/10.1080/20511787.2018.1467197

Graedel, T. E. (1995). Industrial ecology.

Hobson, K., Lynch, N., Lilley, D., \& Smalley, G. (2018). Systems of practice and the Circular Economy: Transforming mobile phone product service systems. Environmental innovation and societal transitions, 26, 147-157.

Irwin, T. (2015). Transition design: A proposal for a new area of design practice, study, and research. Design and Culture, $7(2), 229-246$.

Jia, F., Yin, S., Chen, L., \& Chen, X. (2020). The circular economy in the textile and apparel industry: A systematic literature review. Journal of Cleaner Production, 259, 120728. https://doi.org/10.1016/J.JCLEPRO.2020.120728

Jones, P. H. (2014). Systemic design principles for complex social systems. In G. Metcalf (Ed.), Social systems and design (pp. 91-128). Tokyo: Springer.

JRC, 2014, Environmental improvement potential of textiles (IMPRO-Textiles), JRC Scientific and Technical Reports, Joint Research Centre, Ispra, Italy.

Karell, E., \& Niinimäki, K. (2019). Addressing the Dialogue between Design, Sorting and Recycling in a Circular Economy. 10-12. https://doi.org/10.1080/14606925.2019.1595413

Karell, E., \& Niinimäki, K. (2020). A mixed-method study of design practices and designers' roles in sustainable-minded clothing companies. Sustainability (Switzerland), 12(11). https://doi.org/10.3390/su12114680

Kern, F., Kivimaa, P., \& Martiskainen, M. (2017). Policy packaging or policy patching? The development of complex energy efficiency policy mixes. Energy Research \& Social Science, 23, 1125.

Kern, F., Sharp, H., \& Hachmann, S. (2020). Governing the second deep transition towards a circular economy: How rules emerge, align and diffuse. Environmental Innovation and Societal Transitions, 37, 171-186.

Krauz, A. (2016). Transition management in Montreuil: towards perspectives of hybridisation between 'top-down' and 'bottom-up'transitions. In Governance of urban sustainability transitions (pp. 133-150). Springer, Tokyo.

Lane, R., Gumley, W., Santos, D., Ballie, J., \& Woods, M. (2015). Circular by Design: A model for engaging fashion / textile SME's with strategies for designed reuse. Unmaking Waste 2015 Conference Proceedings, May, 488-522.

Lehner, M., Mont, O., Mariani, G., \& Mundaca, L. (2020). Circular Economy in Home Textiles: Motivations of IKEA Consumers in Sweden. Sustainability. https://doi.org/10.3390/su12125030

Lyle, J. T. (1996). Regenerative design for sustainable development. John Wiley \& Sons.

MacArthur, E. (2013). Towards the circular economy. Journal of Industrial Ecology, 2, 23-44.

Martínez-Alier, J. (2012). Environmental justice and economic degrowth: an alliance between two movements. Capitalism Nature Socialism, 23(1), 51-73.

McDonough, W., \& Braungart, M. (2010). Cradle to cradle: Remaking the way we make things. North point press. 
Mestre, A., \& Cooper, T. (2017). Circular product design. A multiple loops life cycle design approach for the circular economy. Design Journal, 20, S1620-S1635.

https://doi.org/10.1080/14606925.2017.1352686

Mhatre, P., Panchal, R., Singh, A., \& Bibyan, S. (2021). A systematic literature review on the circular economy initiatives in the European Union. In Sustainable Production and Consumption (Vol. 26, pp. 187-202). Elsevier B.V. https://doi.org/10.1016/j.spc.2020.09.008

Moorhouse, D., \& Moorhouse, D. (2017). Sustainable design: circular economy in fashion and textiles. The Design Journal, 20(sup1), S1948-S1959.

Murray, A., Skene, K., \& Haynes, K. (2017). The circular economy: an interdisciplinary exploration of the concept and application in a global context. Journal of business ethics, 140(3), 369-380.

Nikolaou, I. E., Jones, N., \& Stefanakis, A. (2021). Circular Economy and Sustainability: the Past, the Present and the Directions. Circular Economy and Sustainability. https://doi.org/10.1007/s43615021-00030-3

Pauli, G. A. (2010). The blue economy: 10 years, 100 innovations, 100 million jobs. Paradigm publications.

Pirages, D. C. (1977). Sustainable society: implications for limited growth.[16 papers].

Preston, F. (2012). A global redesign? Shaping the circular economy.

Raworth, K. (2017). A Doughnut for the Anthropocene: humanity's compass in the 21st century. The Lancet Planetary Health, 1(2), e48-e49.

Rittel and Webber. (1973). Dilemmas in a general theory of planning. Policy Sciences, 4, 155-169.

Schneider, F., Kallis, G., \& Martinez-Alier, J. (2010). Crisis or opportunity? Economic degrowth for social equity and ecological sustainability. Introduction to this special issue. Journal of cleaner production, 18(6), 511-518.

Sevaldson, B. (2011). Gigamapping: Visualization for complexity and systems thinking in design. Helsinki: Nordic Design Research Conference

Stahel, W. (2010). The performance economy. Springer.

Stebbing, P., \& Tischner, U. (2015). Changing paradigms: designing for a sustainable future. Aalto University.

Sumter, D., de Koning, J., Bakker, C., \& Balkenende, R. (2021). Key competencies for design in a circular economy: Exploring gaps in design knowledge and skills for a circular economy. Sustainability (Switzerland), 13(2), 1-15. https://doi.org/10.3390/su13020776

Thackara, J. (2005). In the Bubble: Designing in a Complex World.

United Nations Environment Programme (2009). Design for sustainability: A Global Guide. UNEP and TU Delft, Paris

Vercalsteren, A., Nicolau, M., \& Lafond, E. (2019). Textiles and the environment in a circular economy.

Von Bertalanffy, L. (1950). An outline of general system theory. British Journal for the Philosophy of science.

Wiener, N. (1948). Cybernetics or Control and Communication in the Animal and the Machine. Technology Press.

Authors Bios:

Eliana Ferrulli is a PhD student in Management Production and Design at Politecnico di Torino (Department of Architecture and Design, 2020-2023). Her doctoral research focuses on fostering industrial innovation towards a Circular Economy framework, with 
particular attention to the textile value chain aiming to build more resilient socio-technical systems, through Systemic Design.

Silvia Barbero, PhD is an Associate Professor at Politecnico di Torino (Department of Architecture and Design) and chair of the Systemic Design Association since its foundation in 2018. She leads Systemic Design research in local economies, policy design,

environmental production, innovation, through collaboration with companies, research centres, national and international networks. 